\title{
Effects of HTR1B 3' region polymorphisms and functional regions on gene expression regulation
}

\author{
Xi Xia, Mei Ding, Jin-feng Xuan, Jia-xin Xing, Hao Pang, Jun Yao, Xue Wu and Bao-jie Wang ${ }^{*}$
}

\begin{abstract}
Background: The HTR1B gene encodes the 5-hydroxytryptamine (5-HT1B) receptor, which is involved in a variety of brain activities and mental disorders. The regulatory effects of non-coding regions on genomic DNA are one of many reasons for the cause of genetic-related diseases. Post-transcriptional regulation that depends on the function of $3^{\prime}$ regulatory regions plays a particularly important role. This study investigated the effects, on reporter gene expression, of several haplotypes of the HTR1B gene (rs6297, rs3827804, rs140792648, rs9361234, rs76194807, rs58138557, and rs13212041) and truncated fragments in order to analyze the function of the $3^{\prime}$ region of HTR1B.

Results: We found that the haplotype, A-G-Del-C-T-Ins-A, enhanced the expression level compared to the main haplotype; A-G-Del-C-G-Ins-A; G-G-Del-C-G-Ins-G decreased the expression level. Two alleles, rs76194807T and rs6297G, exhibited different relative luciferase intensities compared to their counterparts at each locus. We also found that $+2440 \sim+2769$ bp and $+1953 \sim+2311$ bp regions both had negative effects on gene expression.

Conclusions: The $3^{\prime}$ region of HTRIB has a regulatory effect on gene expression, which is likely closely associated with the interpretation of HTR1B-related disorders. In addition, the HTR1B $3^{\prime}$ region includes several effector binding sites that induce an inhibitory effect on gene expression.
\end{abstract}

Keywords: HTR1B, Polymorphism, Gene expression

\section{Background}

Eukaryotic cell gene expression is usually controlled by a precise gene regulatory network. Post-transcriptional regulation plays a particularly important role in gene expression [1], including in the function of the 3' regulatory region on mRNA. The $3^{\prime}$ region varies the regulatory effects with its sequence and structural characteristics, and is involved in mRNA stability, translation, and positioning. The 3' region interacts with many kinds of effectors such as microRNAs (miRNAs) and RNA-binding proteins (RPBs) [2]. MicroRNA is a 22-nucleotide small non-coding RNA that targets a

\footnotetext{
*Correspondence: wangbj77@163.com

School of Forensic Medicine, China Medical University, No. 77 Puhe Road, Shenbei New District, Shenyang 110122, China
}

specific sequence on mRNA, mostly the 3' regulatory region, inducing translational inhibition or mRNA degradation. More than 2000 miRNAs exist. Sixty percent of human transcriptomes are modulated by miRNAs [3]. In addition, the human genome encodes more than 1500 RBPs. The RNA-binding domains of RBPs are often involved in the recognition of the $3^{\prime}$ untranslated region (UTR) [4]. Variations in these regulatory mechanisms may have an impact on disease. Some diseases are more likely to be affected by genetic factors, such as observed in several mental disorders. For example, twin studies have shown that heritability of schizophrenia and autism is about 80 and $76 \%$, respectively [5]. Compared to coding regions that only account for $1 \%$ of the human genome, the genetic associations of many diseases are

C The Author(s). 2020 Open Access This article is licensed under a Creative Commons Attribution 4.0 International License, which permits use, sharing, adaptation, distribution and reproduction in any medium or format, as long as you give appropriate credit to the original author(s) and the source, provide a link to the Creative Commons licence, and indicate if changes were made. The images or other third party material in this article are included in the article's Creative Commons licence, unless indicated otherwise in a credit line to the material. If material is not included in the article's Creative Commons licence and your intended use is not permitted by statutory regulation or exceeds the permitted use, you will need to obtain permission directly from the copyright holder. To view a copy of this licence, visit http://creativecommons.org/licenses/by/4.0/ The Creative Commons Public Domain Dedication waiver (http://creativecommons.org/publicdomain/zero/1.0/) applies to the data made available in this article, unless otherwise stated in a credit line to the data. 
more likely to exist in non-coding sequences such as the 3' UTR [6].

Considering its extensive effects on gene expression microRNA is the primary subject of this study. It is known that miRNAs can suppress mRNA transcription or inhibit protein translation through miRNAmRNA binding [7]. The miRNA regulatory effects are closely related to variations such as polymorphisms or mutations, which are located at miRNA target gene binding sequences. Single nucleotide polymorphisms (SNP) in miRNA target sites are known as polymiRTS, which may produce many functional consequences. They may generate a new miRNA target site or destroy an existing one, or change miRNA-mRNA binding efficiency [8]. Many studies show that existing 3' UTR mutations may affect the function of miRNA and lead to disease risks. In a previous study, the $\mathrm{C}$ allele of rs10759 significantly inhibited the binding of miR-124 to its target gene, the 3'UTR of RGS4, and thus affected susceptibility to schizophrenia [9]. The $H 3 F 3 B$ gene strengthens its interaction with miR-616 through the s1060120 A allele, resulting in posttranscriptional suppression, and is also related to a schizophrenia phenotype [10]. A review by Sethupathy et al. also emphasized the opinion that poly-miRTS is disease related [8].

The 5-hydroxytryptamine receptor $1 \mathrm{~B}$ gene (HTR1B) is associated with multiple psychiatric disorders, including schizophrenia, aggressive behavior, attention deficit hyperactivity disorder (ADHD), and substance abuse [11-13]. The length of the HTR1B gene is $3175 \mathrm{bp}$, located on chromosome 677,460,848-77,464,022 (GRC h38.p7), and contains only one exon. Based on the previous studies, several SNPs are distributed in its coding regions, such as missense mutations rs130060Cys124Phe, rs130061Phe219Leu, rs130063Ile367Val, and rs130064 Glu374Lys, synonymous mutations rs6296Val287 and rs6298Ser43 [14]. In our previous study, six SNPs (rs4 140535, rs1778258, rs17273700, rs1228814, rs11568817, and rs130058) were found in the 5' region of the HTR1B gene, and other seven SNPs (rs6297, rs3827804, rs140792648, rs9361234, rs76194807, rs58138557, and rs13212041) were found in the 3 ' region of the HTR1B gene [15]. This study will focus on the SNPs in the 3 ' region of the HTR1B gene, which are not presented to affect any gene expression rate in eQTL GTEX Consortium data. Although a previous study has shown that the HTR1B rs13212041 G allele attenuates miRNA-mediated mRNA silencing [12], it is very limited in explaining the regulatory mechanisms behind these associations. In addition, extracellular miRNAs can also exist in the blood circulatory system. Most circulating miRNAs are stably present in lipid or lipoprotein complexes, such as apoptotic bodies, microvesicles, or exosomes, which act as biological markers for the diagnosis, treatment, or prognosis of complex diseases [16].

We investigated the effects of several haplotypes of the HTR1B gene, and truncated fragments of the 3 ' region of $H T R 1 B$, on reporter gene expression in order to analyze the function of the 3 ' region.

\section{Results}

The regulatory effects of polymorphisms of the $3^{\prime}$ region of HTR1B

Haplotype recombinants were transfected into SK-N-SH, HEK-293, and U87 cell lines. Differences in the relative fluorescence intensities among groups were present in SK-N-SH and HEK-293 cells $(P=3.000$ E-05 and $P=$ 9.7158E-09, respectively), rather than U87 cells $(P=$ 0.068 ). The data of our previous study indicated that the H1 haplotype was the major haplotype [15], having a frequency of $62.3 \%$ in the northern Han Chinese population. The $\mathrm{H} 4$ haplotype showed a higher relative fluorescence intensity $(P=0.032)$ in SK-N-SH cells. We noticed that for $\mathrm{H} 1$ and H4 haplotypes, a difference occurred at rs76194807 (G/T), suggesting that the rs76194807T allele led to an enhanced level of expression. In comparison, in HEK-293 cells we found that the relative fluorescence intensity of the H3 haplotype was lower than that of the major haplotype $(P=1.701 \mathrm{E}-04)$. In addition, a difference was also present between the relative fluorescence intensities of $\mathrm{H} 2$ and $\mathrm{H} 3$ haplotypes $(P=4.148 \mathrm{E}-04)$. Variations at rs6297 (A/G) indicated that this allele had an inhibitory effect on gene expression (Fig. 1).

\section{Analysis of functional sequences of the 3 ' region of HTR1B}

Truncated sequence recombinants were transfected into SK-N-SH, HEK-293, and U87 cell lines. Changes in the relative fluorescence intensities between the truncated fragments, D3 and D4, as well as D5 and D6, only existed in SK-N-SH cells. The truncated fragments, D0 and D1, as well as D2 and D3 showed differences in relative fluorescence intensity in two cell lines. Upward trends in the relative fluorescence intensities between the truncated fragments, D4 and D5, as well as between D6 and D7, were present in all cell lines (Fig. 2).

\section{Results of microRNA predictions}

TarBase v.8 yields hsa-miR-21-3p, hsa-miR-941, hsa-miR129-2-3p, hsa-miR-16-5p, hsa-miR-182-5p, and hsa-miR26a-5p, which could target HTR1B. All these results were derived from high throughput experiment method.

\section{Discussion}

The functional characteristics of the 3 ' region of $H T R 1 B$ are closely related to the interpretation of HTR $1 B$-associated studies. In SK-N-SH cells, the H4 haplotype and 

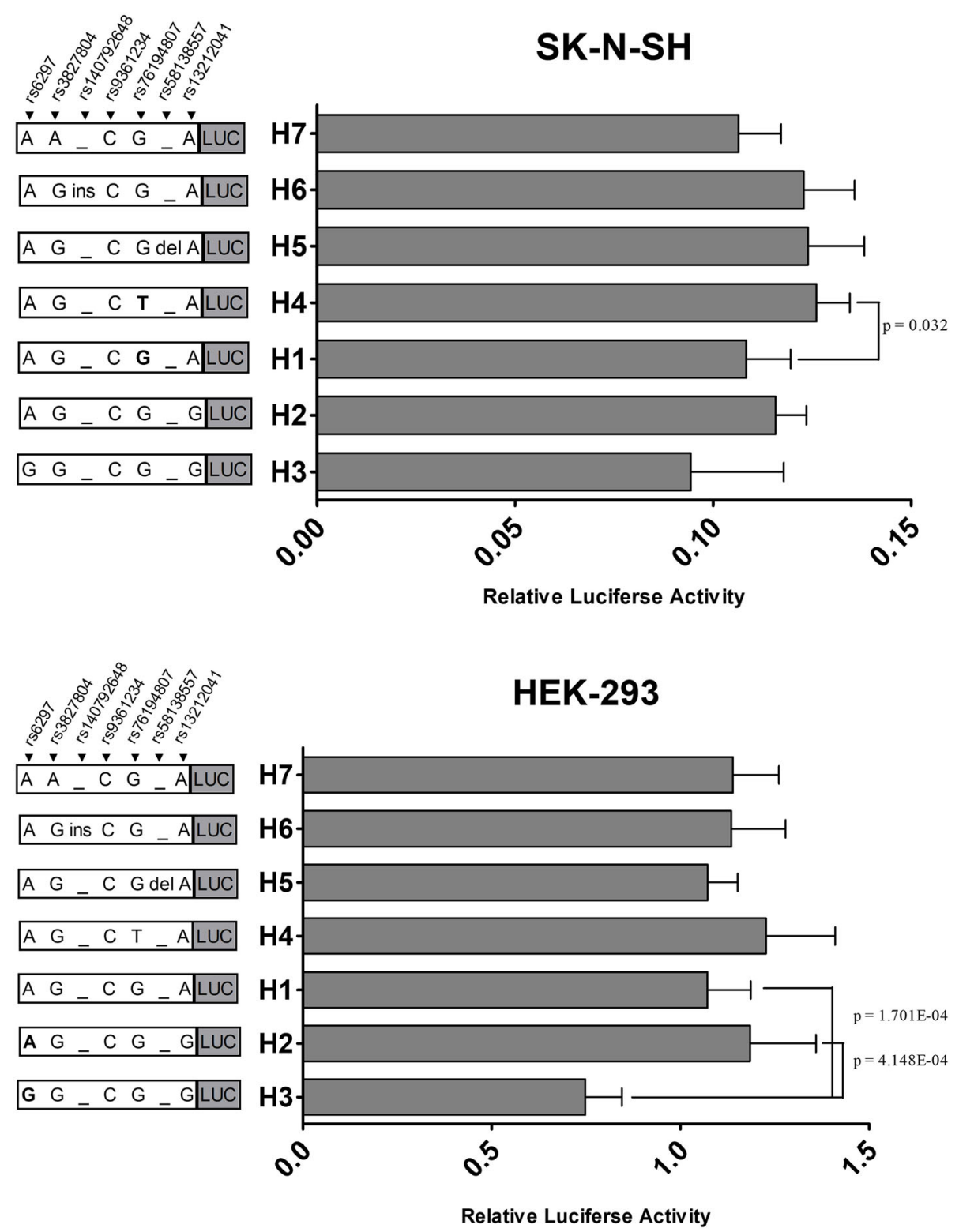

Fig. 1 Relative fluorescence intensities of haplotype recombinants in SK-N-SH and HEK-293 cells. The haplotypes, from H2 to H7, were compared with the major haplotype, $\mathrm{H} 1$; the $\mathrm{H} 2$ haplotype was compared to the $\mathrm{H} 3$ haplotype. The $\mathrm{H} 4$ haplotype showed a higher relative fluorescence intensity than that of the HI haplotype in SK-N-SH cells. The relative fluorescence intensity of the H3 haplotype was lower than that of H1and H2 haplotypes in HEK-293 cells

the rs76194807T allele led to a higher level of gene expression, but previous studies have not been undertaken on either the function of rs76194807 or its association with disease. In HEK-293 cells, the H3 haplotype showed the lowest relative fluorescence intensity, and significantly suppressed gene expression compared to all other haplotypes. We also found that rs6297 $(\mathrm{A} / \mathrm{G})$ is functional, with this allele having a negative regulatory effect. This suggested that rs6297 and a potentially schizophrenia-associated polymorphism, rs1778258, had a moderate linkage relationship [15].
Researchers also found that the A-A-A-C haplotype of rs6297, rs130058, rs1213366, and rs1213371 had a potential relationship with schizophrenia in the Spanish population [11]. The rs6297G allele is also associated with susceptibility to Raynaud's disease in an occupationally exposed Han Chinese population [17]. Therefore, the effect of rs6297 on gene expression is probably related to the mechanisms of these genetic-related diseases.

This study also investigated the functional sequence in the $3^{\prime}$ region of HTR1B using truncated fragments in 


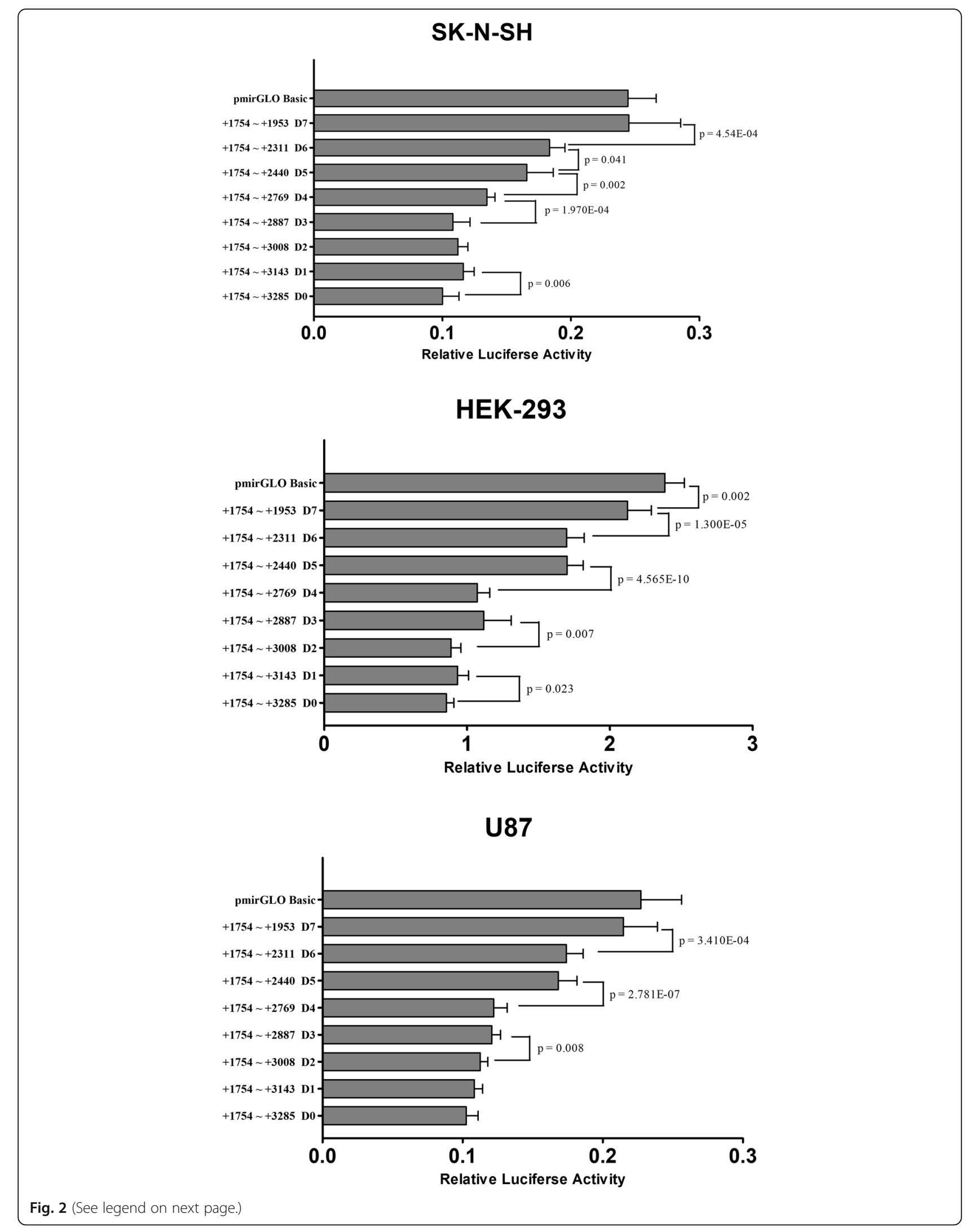


(See figure on previous page.)

Fig. 2 Relative fluorescence intensities of the truncated sequence recombinants in SK-N-SH, HEK-293, and U87 cells. Two regions, (+ 1754 to + 2769 ) versus $(+1754$ to +2440$)$, and $(+1754$ to +2311$)$ versus $(+1754$ to +1953$)$, showed significant regulatory effects on gene expression between in all three cell lines. Relative fluorescence intensity is expressed as the mean \pm standard deviation (SD). The no-insert pmirGLO vector (pmirGLO basic) is a control plasmid

order to narrow the targets that were potential binding sequences to effectors. The truncated sequence recombinants were transfected into SK-N-SH, HEK-293, and U87 cell lines. Each fragment was compared to a shorter one to identify the regulatory effect of the deleted region. It was found that truncated fragments D0 and D1, D2 and D3, D4 and D5, and D6 and D7 showed differences in at least two different cell lines. In particular, the truncated fragments D4 and D5, and D6 and D7, exhibited upward trends in all three cell lines. Therefore, the deleted sequences $+2440 \sim+2769$ bp (D4 versus D5), and $+1953 \sim+2311$ bp (D6 versus D7) are potential effector-binding regions. In addition, Jensen et al. found that miR-96 could interact with rs13212041,[9] which was located in deleted fragment $+2440 \sim+2769$ bp (D4 versus D5). However, we did not find a similar effect in this study. Since SK-N-SH, HEK-293, and U87 cell lines were used in our study while a different cell line, HeLa, was used by Jensen et al. [12], the inconsistency in results is probably derived from the tissue-specific regulation of miRNA. It also indicates that other regulatory elements other than miR-96 may exist in the + $2440 \sim+2769 \mathrm{bp}$ region to inhibit the expression of HTR1B. We also observed that in SK-N-SH cells, rs76194807 $\mathrm{T}$ and $\mathrm{G}$ alleles had different effects on expression level. rs76194807 is located at $+2129 \mathrm{bp}$, which happened to within the effective region of +1953 $\sim+2311$ bp. rs6297 A and G alleles are also involved in changing the gene expression level in HEK-293 cells. rs6297 is located at $+1802 \mathrm{bp}$, which is included in the effective region of $+1754 \sim+1953$ bp (Fig. 2). The mechanism underlying the potential effector-binding regions could be associated with the functional polymorphisms of the HTR1B gene.

Based on our results, all the truncated regions that caused the changes showed the down-regulating effect to gene expression, and as far as we know, the most classic mechanism of microRNA is to bind to the 3 ' UTR region and mediate the suppression of gene expression. Predicting miRNAs binding to $H T R 1 B$, we found that starBase and RNAHybrid yielded miR-96 [12]. The function of miRNAs on gene regulation is very extensive. A miRNA can act on multiple genes, and one gene is usually modulated by several miRNAs. TarBase v8 predicted multiple miRNAs that could target HTR1B, including miR-21-3p, miR-941, miR-129-2-3p, miR-182$5 p$, and miR-26a-5p. Liu et al. found that miR-21 in peripheral blood is a highly sensitive and specific biomarker for the diagnosis of schizophrenia [18]. MicroR-21 was also significantly decreased in the peripheral blood of schizophrenic patients after antipsychotic treatment [16]. Transgenic mice overexpressing miR-26a-2 in serotonergic neurons displayed improved behavioral resiliency to social defeat while mice with miR-26a-2 knockdown in serotonergic neurons were more likely to be anxious. MicroR-26a-2 in the mouse dorsal raphe nucleus was also increased after antidepressant therapy [19]. Currently, no evidence exists that Homo sapiens (hsa)-miR-129 is associated with mental disorders, but it is closely related to the occurrence and progression of cancers [20]. MicroR-96 has been shown by Jensen et al. to have an association with aggressive behavior through interaction with $H T R 1 B$ [12]. Hsa-miR-96 is also linked to hsa-miR-182 and hsamiR-183, which are co-located on chromosome 7 and constitute a miRNA cluster. MicroR-183, miR-96, and miR-182 belong to the miR-183 family and are highly conserved. The previous study found that rs2402959 and rs6965643 at the miRNA 96-182-183 cluster correlated with ADHD and substance use disorders [21]. rs76481776 polymorphism caused variant pre-miR-182 associated with the dysregulation of circadian rhythms in patients with major depression and insomnia [22]. In another study that used addiction as a model of synaptogenesis and learning, injections of nicotine, cocaine or amphetamine caused changes in miRNA expression throughout the brain; miR-182 showed increased expression in the midbrain with all three drugs. This suggested that miR-182 may be involved in the regulation of addictive pathways and synaptogenesis [23].

\section{Conclusions}

HTR1B 5' regulatory region polymorphisms have regulatory effects on gene expression, and $+2440 \sim+2769$ bp and $+1953 \sim+2311$ bp regions are potential effectorbinding regions that both suppress gene expression. However, further research is needed on the functional effectors binding to HTR $1 B$ and their association with diseases.

\section{Methods}

\section{Samples}

We selected genomic DNA samples, based on our previous study [15], containing seven haplotypes (consist of 
Table 1 Comparison of single nucleotide polymorphisms in haplotype recombinants

\begin{tabular}{|c|c|c|c|c|c|c|c|c|}
\hline Haplotype & Frequency & rs6297 & rs3827804 & rs140792648 & rs9361234 & rs76194807 & rs58138557 & rs13212041 \\
\hline $\mathrm{H} 1$ & 0.481 & $A$ & G & Del & C & G & Ins & $A$ \\
\hline $\mathrm{H} 2$ & 0.127 & A & G & Del & C & G & Ins & G \\
\hline H3 & 0.126 & G & G & Del & C & G & Ins & G \\
\hline $\mathrm{H} 4$ & 0.123 & A & G & Del & C & $\mathrm{T}$ & Ins & A \\
\hline H5 & 0.095 & A & G & Del & $\mathrm{T}$ & G & Del & A \\
\hline H6 & 0.026 & A & G & Ins & C & G & Ins & $A$ \\
\hline $\mathrm{H} 7$ & 0.013 & A & A & Del & $C$ & G & Ins & A \\
\hline
\end{tabular}

rs6297, rs3827804, rs140792648, rs9361234, rs76194807, rs58138557, and rs13212041), to construct pGL3 recombinants. The haplotype $\mathrm{H} 1$ is the major haplotype which has the highest frequency (Table 1). The target gene was obtained from GenBank using the reference sequence, NC_000006.12 (Homo sapiens chromosome 6, GRCh38.p7 Primary Assembly).

\section{Construction of haplotype recombinants}

DNA samples containing haplotypes $\mathrm{H} 1$ to $\mathrm{H} 7$ were used as DNA templates for amplification. The target fragments were from +1754 bp to +3285 bp (transcription start site [TSS], +1), including the whole $3^{\prime}$ UTR. The $5^{\prime}$ end of the primers had introduced XhoI and XabI cleavage sites. The primer sequences were 5 ' -CCGCTCGAGAAACTGA TACGTTTTAAGTG-3' (sense), and 5'- GCTCTAGA GCGTTTCCTGATTGTTAGTAAGTC -3' (antisense). The purified target fragments were cloned into the pBM20S vector (Biomed, Beijing, China), and then recloned into the XhoI/XabI site of the pmirGLO reporter vector (Promega, Madison, WI, USA). The target haplotype of each construct was verified by DNA sequencing.

\section{Construction of truncated sequence recombinants}

The target sequences were a series of DNA fragments with a common start at +1754 bp (TSS, + 1). The longest fragment was from +1754 to +3285 bp, and the shortest fragment was from +1754 to + $1953 \mathrm{bp}$ (Fig. 3). The primers used for PCR are shown in Table 2. XhoI and XabI cleavage sites were introduced into the $5^{\prime}$ end of the primers. Truncated sequence recombinants were constructed and verified in the same manner as for the haplotype recombinants.

\section{Cell lines and cell culture}

Human neuroblastoma (SK-N-SH), embryonic kidney (HEK-293), and glioma (U87) cell lines [24, 25], obtained from the Cell Bank of the Chinese Academy of Sciences (Shanghai, China), were cultured in a humidified $37^{\circ} \mathrm{C}$ environment at $5 \% \mathrm{CO}_{2}$. SK-N-SH cells were grown in HyClone ${ }^{\oplus}$ DMEM supplemented with $15 \%$ fetal bovine serum (FBS; PAN-Biotech, Aidenbach, Germany). HEK-293 and U87 cells were grown in KeyGEN BioTECH ${ }^{\odot}$ DMEM in the presence of $10 \%$ FBS.

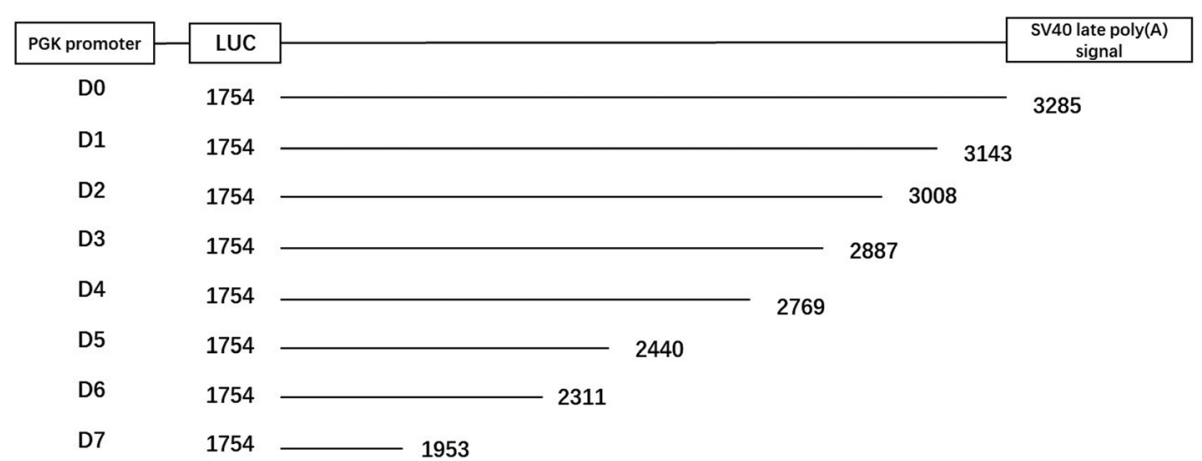

Fig. 3 Truncated sequence recombinants in the $3^{\prime}$ regulatory region of HTRIB. The target gene was obtained using the GenBank reference sequence NC_000006.12 (Homo sapiens chromosome 6, GRCh38.p7 Primary Assembly). The DNA fragments shared a common 5' end at + 1754 bp $($ TSS, + 1) 
Table 2 Primer sequences of the target fragments

\begin{tabular}{|c|c|c|}
\hline Primer & Length & Sequences \\
\hline Common end (+ 1754)-F & & 5' CCGCTCGAGAAACTGATACGTTITAAGTG 3' \\
\hline D0 (+ 1754 + 3285)-R & $1532 \mathrm{bp}$ & 5' GCTCTAGAGCGTTTCCTGATTGTTAGTAAGT 3' \\
\hline D1 (+ 1754 + +3143)-R & $1390 \mathrm{bp}$ & 5' GCTCTAGAGCTTCTCCTGCCCAAACTTC 3' \\
\hline D2 (+ 1754 + 3008)-R & $1255 \mathrm{bp}$ & 5' GCTCTAGAGCTATGTTAGCACACAAGGAATC 3' \\
\hline D3 (+ 1754 + 2887)-R & $1134 \mathrm{bp}$ & 5' GCTCTAGAGCCCATTCCTCAATTGTGTAAG 3' \\
\hline D4 (+ 1754 + 2769)-R & $1016 \mathrm{bp}$ & 5' GCTCTAGAGCTCGGTITACCAATTGCAT 3' \\
\hline D5 (+ 1754 + 2440)-R & $687 \mathrm{bp}$ & 5' GCTCTAGAGCTCTCAGCATCAGAATTITG 3' \\
\hline D6 (+ 1754 + 2311)-R & $558 \mathrm{bp}$ & 5' GCTCTAGAGCAATGATGCCAAAGTAACTGTT 3' \\
\hline D7 (+ 1754 + 1953)-R & $200 \mathrm{bp}$ & 5' GCTCTAGAGCTATTCTGGCTTCTCAGGATC 3' \\
\hline
\end{tabular}

\section{Transfection and dual-luciferase reporter assay}

Cells were inoculated into 24 -well plates $\left(2 \times 10^{5}\right.$ cells/ well) and grown to $90 \%$ confluence. Transient transfection was performed using Lipofectamine ${ }^{\circ} 3000$ reagent (Invitrogen, Carlsbad, CA, USA), according to the manufacturer's protocol. Cell lysates were collected for reporter assay 28 to $30 \mathrm{~h}$ post-transfection using a DualLuciferase $^{\circ}$ Reporter Assay System (Promega, Madison, WI, USA).

\section{microRNA target sites predictions}

MicroRNA target sites predictions were carried out using a TarBase prediction platform [26].

\section{Statistical analysis}

Firefly luciferase activity was divided by that of Renilla luciferase activity (LUC/TK) to yield the relative luciferase intensity. All groups of data were verified to follow a normal distribution. Differences in relative fluorescence intensity between each two haplotype recombinants were calculated using Bonferroni or Dunnett's T3 test (based on the result of Levene's test) following one-way analysis of variance. Differences in the relative fluorescence intensities between truncated sequence recombinants (D0 versus D1, D1 versus D2, D2 versus D3, D3 versus D4, D4 versus D5, D5 versus D6, D6 versus D7, D7 versus pmirGLO basic vector) were calculated using the independent-samples $t$-test. Calculations were carried out by SPSS22 software (IBM, Armonk, NY, USA). $P<0.05$ indicated statistical significance.

\section{Abbreviations \\ HTR1B: Serotonin receptor 1B; 5-HT1B: 5-hydroxytryptamine receptor 1B; SNP: Single-nucleotide polymorphism; LD: Linkage disequilibrium; \\ UTR: Untranslated region; ADHD: Attention deficit hyperactivity disorder; \\ TSS: Transcription start site}

\section{Acknowledgements}

We thank all the members of the Forensic Genetics and Biology Department of China Medical University for assistance with the experimental design, technical guidance, and financial support.

\section{Authors' contributions}

BW conceived and designed this study. XX conducted the experiment, statistical analyses, and finished the manuscript. MD, JX1, JX2, HP, JY, and XW played important roles in interpreting the results and providing relevant assistance in conducting study. All authors have read and approved the manuscript.

\section{Funding}

This work was supported by China Medical University. The funding body provided the financial means for the authors to carry out the study, but played no roles in study design, data collection and analysis, interpretation of data and manuscript preparation.

\section{Availability of data and materials}

The datasets used in this study are available from the corresponding author upon reasonable request.

\section{Ethics approval and consent to participate}

The study was approved by the China Medical University Review Committee and performed according to the national guidelines. All subjects and/or patient guarantors provided written informed consent for participation in this study.

Consent for publication

Not applicable.

\section{Competing interests}

The authors declare that they have no competing interests.

Received: 12 March 2020 Accepted: 12 July 2020

Published online: 20 July 2020

References

1. Schwanhausser B, Busse D, Li N, Dittmar G, Schuchhardt J, Wolf J, Chen W, Selbach M. Global quantification of mammalian gene expression control. NATURE. 2011;473(7347):337-42.

2. Steri M, Idda ML, Whalen MB, Orru V. Genetic variants in mRNA untranslated regions. Wiley Interdiscip Rev RNA. 2018;9(4):e1474.

3. Duchaine TF, Fabian MR. Mechanistic Insights into MicroRNA-Mediated Gene Silencing. Cold Spring Harb Perspect Biol. 2019;11(3).

4. Hentze MW, Castello A, Schwarzl T, Preiss T. A brave new world of RNAbinding proteins. Nat Rev Mol Cell Biol. 2018;19(5):327-41.

5. Sullivan PF, Kendler KS, Neale MC. Schizophrenia as a complex trait: evidence from a meta-analysis of twin studies. Arch Gen Psychiatry. 2003; 60(12):1187-92.

6. Hindorff LA, Sethupathy $P$, Junkins HA, Ramos EM, Mehta JP, Collins FS, Manolio TA. Potential etiologic and functional implications of genome-wide association loci for human diseases and traits. Proc Natl Acad Sci U S A 2009;106(23):9362-7. 
7. Winter J, Jung S, Keller S, Gregory RI, Diederichs S. Many roads to maturity: microRNA biogenesis pathways and their regulation. Nat Cell Biol. 2009;11(3): 228-34.

8. Sethupathy P, Collins FS. MicroRNA target site polymorphisms and human disease. Trends Genet. 2008;24(10):489-97.

9. Gong $Y$, Wu CN, Xu J, Feng G, Xing QH, Fu W, Li C, He L, Zhao XZ Polymorphisms in microRNA target sites influence susceptibility to schizophrenia by altering the binding of miRNAs to their targets. Eur Neuropsychopharmacol. 2013;23(10):1182-9.

10. Manley W, Moreau MP, Azaro M, Siecinski SK, Davis G, Buyske S, Vieland V, Bassett AS, Brzustowicz L. Validation of a microRNA target site polymorphism in $\mathrm{H} 3 \mathrm{~F} 3 \mathrm{~B}$ that is potentially associated with a broad schizophrenia phenotype. PLoS One. 2018;13(3):e194233.

11. Gilabert-Juan J, Ivorra JL, Tolosa A, Gratacos M, Costas J, Sanjuan J, Molto MD. Potential involvement of serotonin receptor genes with age of onset and gender in schizophrenia: a preliminary study in a Spanish sample. Psychiatry Res. 2011;186(1):153-4.

12. Jensen KP, Covault J, Conner TS, Tennen H, Kranzler HR, Furneaux HM. A common polymorphism in serotonin receptor 1B mRNA moderates regulation by miR-96 and associates with aggressive human behaviors. Mol Psychiatry. 2009;14(4):381-9.

13. Bidwell LC, Gray JC, Weafer J, Palmer AA, de Wit H, Mackillop J. Genetic influences on ADHD symptom dimensions: examination of a priori candidates, gene-based tests, genome-wide variation, and SNP heritability. Am J Med Genet B Neuropsychiatr Genet. 2017;174(4):458-66.

14. Sanders AR, Cao Q, Taylor J, Levin TE, Badner JA, Cravchik A, Comeron JM, Naruya S, Del RA, Salvi DA, et al. Genetic diversity of the human serotonin receptor 1B (HTR1B) gene. Genomics. 2001;72(1):1-14.

15. Xia X, Ding $M$, Xuan JF, Xing JX, Pang H, Wang BJ, Yao J. Polymorphisms in the human serotonin receptor $1 \mathrm{~B}$ (HTR1B) gene are associated with schizophrenia: a case control study. BMC Psychiatry. 2018;18(1):303.

16. Kosaka N, Iguchi H, Ochiya T. Circulating microRNA in body fluid: a new potential biomarker for cancer diagnosis and prognosis. Cancer Sci. 2010; 101(10):2087-92.

17. Chen $Q$, Lang L, Xiao B, Lin H, Yang A, Li H, Tang S, Huang H. HTR1B gene variants associate with the susceptibility of Raynauds' phenomenon in workers exposed hand-arm vibration. Clin Hemorheol Microcirc. 2016;63(4):335-47.

18. Liu S, Zhang F, Wang X, Shugart YY, Zhao Y, Li X, Liu Z, Sun N, Yang C, Zhang $K$, et al. Diagnostic value of blood-derived microRNAs for schizophrenia: results of a meta-analysis and validation. Sci Rep. 2017;7(1):15328.

19. Xie L, Chen J, Ding YM, Gui XW, Wu LX, Tian S, Wu W. MicroRNA-26a-2 maintains stress resiliency and antidepressant efficacy by targeting the serotonergic autoreceptor HTR1A. Biochem Biophys Res Commun. 2019; 511(2):440-6.

20. Bandres E, Agirre X, Bitarte N, Ramirez N, Zarate R, Roman-Gomez J, Prosper $F$, Garcia-Foncillas J. Epigenetic regulation of microRNA expression in colorectal cancer. Int J Cancer. 2009;125(11):2737-43.

21. Sanchez-Mora C, Ramos-Quiroga JA, Garcia-Martinez I, Fernandez-Castillo N, Bosch R, Richarte V, Palomar G, Nogueira M, Corrales M, Daigre C, et al. Evaluation of single nucleotide polymorphisms in the miR-183-96-182 cluster in adulthood attention-deficit and hyperactivity disorder (ADHD) and substance use disorders (SUDs). Eur Neuropsychopharmacol. 2013;23(11):1463-73.

22. Saus E, Soria V, Escaramis G, Vivarelli F, Crespo JM, Kagerbauer B, Menchon JM, Urretavizcaya M, Gratacos M, Estivill X. Genetic variants and abnormal processing of pre-miR-182, a circadian clock modulator, in major depression patients with late insomnia. Hum Mol Genet. 2010;19(20):4017-25.

23. Banks SA, Pierce ML, Soukup GA. Sensational MicroRNAs: neurosensory roles of the MicroRNA-183 family. Mol Neurobiol. 2019.

24. Kaushik G, Xia Y, Pfau JC, Thomas MA. Dysregulation of autism-associated synaptic proteins by psychoactive pharmaceuticals at environmental concentrations. Neurosci Lett. 2017;661:143-8.

25. Salim K, Fenton T, Bacha J, Urien-Rodriguez H, Bonnert T, Skynner HA, Watts E, Kerby J, Heald A, Beer M, et al. Oligomerization of G-protein-coupled receptors shown by selective co-immunoprecipitation. J Biol Chem. 2002; 277(18):15482-5.

26. Karagkouni D, Paraskevopoulou MD, Chatzopoulos S, Vlachos IS, Tastsoglou S, Kanellos I, Papadimitriou D, Kavakiotis I, Maniou S, Skoufos G, et al. DIANA-TarBase v8: a decade-long collection of experimentally supported miRNA-gene interactions. Nucleic Acids Res. 2018;46(D1):D239-45.

\section{Publisher's Note}

Springer Nature remains neutral with regard to jurisdictional claims in published maps and institutional affiliations.

\section{Ready to submit your research? Choose BMC and benefit from:}

- fast, convenient online submission

- thorough peer review by experienced researchers in your field

- rapid publication on acceptance

- support for research data, including large and complex data types

- gold Open Access which fosters wider collaboration and increased citations

- maximum visibility for your research: over $100 \mathrm{M}$ website views per year

At $\mathrm{BMC}$, research is always in progress.

Learn more biomedcentral.com/submissions 